\title{
An Experimental Study on the Accessory Optic System in the Rabbit*
}

\author{
By \\ T. Ban, T. Ôki and K. Zyo \\ Department of Anatomy, Osaka University Medical School, Japan
}

\section{Introduction}

On the fiber connection of the mammalian retinal fibers, many observations have been worked out during the last several decades. At present it is generally accepted that the retinal fibers terminate in the lateral geniculate body, superior colliculus and other regions in the diencephalon and mesencephalon. Of these the terminations in the hypothalamus and in the ventral tegmental regions of the midbrain have been the most disputable ones. A survey of literatures treating the optic fiber connection makes it apparent that the descriptions by different authors are not all in accord with each other in detail. This seems to be partly due to the difference of animals and/or stain techniques employed and partly due to the different interpretations of the histological pictures of the material.

Recently $\mathrm{Knoche}$ ('56) claimed to have first observed the 'retino-hypothalamische Bahn' mainly with Bielschowsky technique in rabbit, dog and man. Later Blü mcke ('58) confirmed $\mathrm{Kn} \mathrm{o-}$ $\mathrm{c} h$ e's view with the same technique in guinea pig and cat. $\mathrm{H}$ a n d a ('51) investigated the fiber connection between the retina and the hypothalamus in a series of mammals with Marchi technique and proved four different routs in rabbit and guinea pig and three in cat and rat by which the retinal fibers get to the hypothalamus. (He reported in Japanese, so that his work has been escaping from the attention of the most authors. His work was explained by $\mathrm{B}$ a $\mathrm{n}$ ('64) in English.) However, $\mathrm{Ha} \mathrm{y} \mathrm{how} \mathrm{('59),} \mathrm{H}$ a y how et al. ('60) and Giolli ('63) denied the existence of the retinal fibers terminating in the hypothalamus in their Nauta preparations of cat, rat

* This paper is dedicated to the late Prof. T. Taniguchi, Keio University Medical School, in memory of his great contribution to the Japanese Society of Anatomists.

This work was supported by a grant for scientific research from the Ministry of Education. 
and monkey respectively.

Nauta technique has introduced new interpretations as to the terminal nuclei of the accessory optic tracts. The lateral termine nucleus ( $\mathrm{H}$ a y how '59, in cat; $\mathrm{H}$ a $\mathrm{y} \mathrm{how}$ et al. '60, in rat; $\mathrm{Ni}$ imi et al. ' 61 , in rabbit) has been revealed to have synaptic relation with the accessory optic fibers which enclose the nucleus. This view was established first by Nauta technique with its merit of being able to differentiate the terminal degeneration from the passing degeneration. Recent Nauta studies seem to have also established the existence of the connection between the so-called anterior and posterior accessory optic tracts. $\mathrm{H}$ a y how et al. ('60) figured up only one integral accessory optic system in rat. Of course, this connection between two accessory optic tracts is not a new idea, but what is new in this respect is that the terminations were certified by the terminal degenerations of Nauta technique.

The regional share in the composition of the accessory optic system is not yet well established. Descriptions on this matter are very scanty. B rouw e r et al. ('23) studied the retinal projection in the diencephalon and mesencephalon after regional destruction of the retina in rabbit with Marchi technique, but his description on the accessory optic tracts is not precise.

The discrepancies of opinions or new interpretations by Nauta technique in the field of the accessory optic system urged us to reexamine the matter with Marchi technique in consideration of

\section{Abbreviations}

\begin{tabular}{|c|c|}
\hline APL & Area preoptica lateralis \\
\hline APM & Area preoptica medialis \\
\hline BQS & $\begin{array}{l}\text { Brachium quadrigeminum } \\
\text { superius }\end{array}$ \\
\hline CHOP & Chiasma opticum \\
\hline $\mathrm{CI}$ & Capsula interna \\
\hline COLS & Colliculus superior \\
\hline DSOVV & $\begin{array}{l}\text { Pars ventralis of the decus- } \\
\text { satio supraoptica ventralis } \\
\text { (Gudden's commissure) }\end{array}$ \\
\hline $\mathrm{F}$ & Columna fornicis descendens \\
\hline GM & Corpus geniculatum mediale \\
\hline GL & Corpus geniculatum laterale \\
\hline LAMT & Lamina terminalis \\
\hline LH & $\begin{array}{l}\text { Nucleus hypothalamicus } \\
\text { lateralis }\end{array}$ \\
\hline NII & Nervus opticus \\
\hline OTEG & Nucleus opticus tegmenti \\
\hline
\end{tabular}

\begin{tabular}{|c|c|}
\hline PC & Pedunculus cerebri \\
\hline Preop. Cor & $\begin{array}{l}\text { Preoptic component of } \\
\text { the accessory optic system }\end{array}$ \\
\hline SN & Substantia nigra \\
\hline SOPD & $\begin{array}{l}\text { Pars dorsolateralis of the } \\
\text { nucleus supraopticus }\end{array}$ \\
\hline SOPV & $\begin{array}{l}\text { Pars ventromedialis of the } \\
\text { nucleus supraopticus }\end{array}$ \\
\hline SUB & $\begin{array}{l}\text { Nucleus subthalamicus } \\
\text { (corpus Luysi) }\end{array}$ \\
\hline Supraop. & $\begin{array}{l}\text { Comp. Supraoptic component } \\
\text { of the accessory optic system }\end{array}$ \\
\hline TOAA & $\begin{array}{l}\text { Tractus opticus accessorius } \\
\text { anterior }\end{array}$ \\
\hline TOAP & $\begin{array}{l}\text { Tractus opticus accessorius } \\
\text { posterior }\end{array}$ \\
\hline TOP & Tractus opticus \\
\hline VIII & Ventricus tertius \\
\hline
\end{tabular}


merits and demerits of the technique itself and with reference to the regional share of the retina in the composition of the accessory optic system in the rabbit.

\section{Materials and Methods}

Six healthy adult rabbits $(2.4 \sim 2.5 \mathrm{~kg})$ were used in the present study. One rabbit provided the normal control and frontal brain sections were stained alternately with Weil's stain and Nissl stain. Another rabbit was used for the unilateral destruction of the total retinal field and other four rabbits were for the unilateral destruction of the regional fields, namely the superior, inferior, medial and lateral quadrant respectively. Animals were anaesthetized with pentobarbital sodium and the operations were executed under the possibly aseptic conditions. For the destruction of the total retinal field, the eye-ball was enucleated and for the partial destruction, the retina was electro-coagulated through the sclera with a pin-like electrode of the high-frequency coagulator $(200 \mathrm{kc} / \mathrm{s})$ under the naked eye. The lesion extended from the conjunctival margin in front to the vicinity of the exit of the optic nerve behind. After 14 days of the postoperative survival period, the animals were perfused with M üller's solution. Complete serial frontal sections of the brains were studied by means of Marchi technique.

\section{Results}

Examination of the material disclosed the following four groups of retinal fibers terminating in the hypothalamus and in the ventral tegmental regions of the midbrain, i. e. (1) preoptic component, (2) supraoptic component, (3) anterior accessory optic tract and (4) posterior accessory optic tract. The whole scheme as to course and termination of these fiber groups is depicted in Fig. 12.

(1) Preoptic component (Preop. Comp. in Fig. 12): At the level of the most rostral tip of the optic chiasm where the optic nerves of both sides are still separate from each other, a few degenerated granules were observed to leave the affected optic nerve from its mediodosal corner and descend dorsocaudad, diverging laterally almost in parallel with the dorsal surface of the chiasm to finish their course partly in the grey substance just ventral to the optic recess which was identified as a part of the lamina terminalis (Fig. 1), and partly more caudally in the medial preoptic area (Fig. 2). 


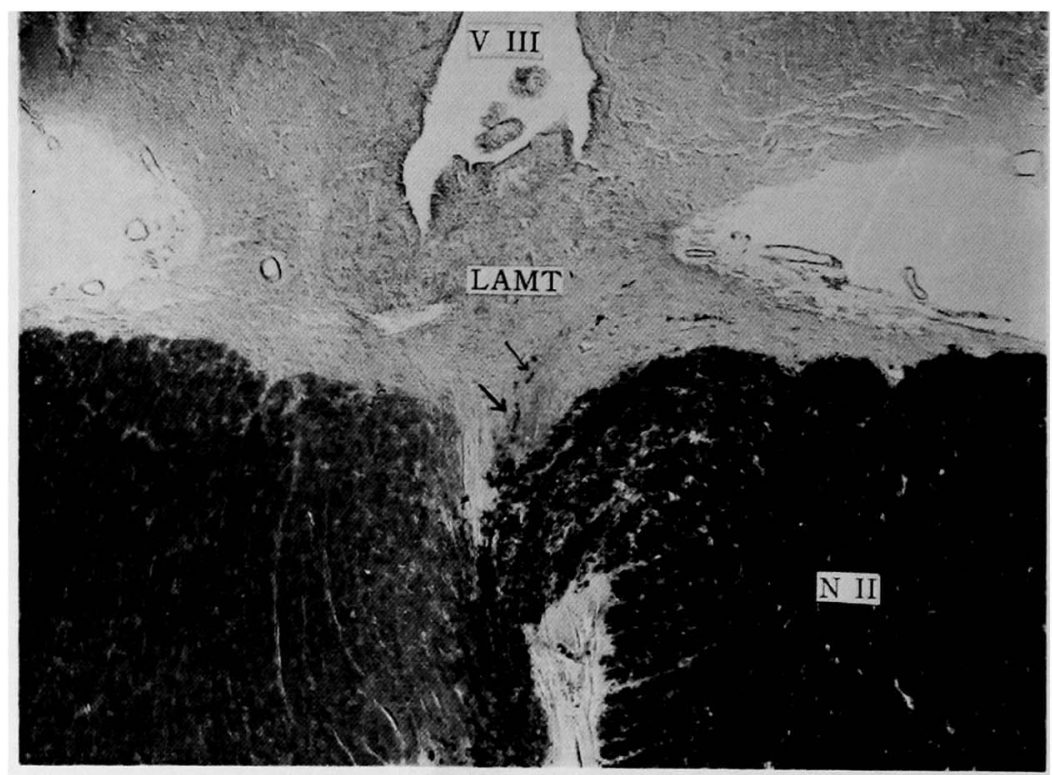

Fig. 1. Preoptic component is shown (arrows) to leave the ipsilateral optic nerve (N II) and descend through the lamina terminalis (LAMT). Frontal section. Marchi. $\times 50$.

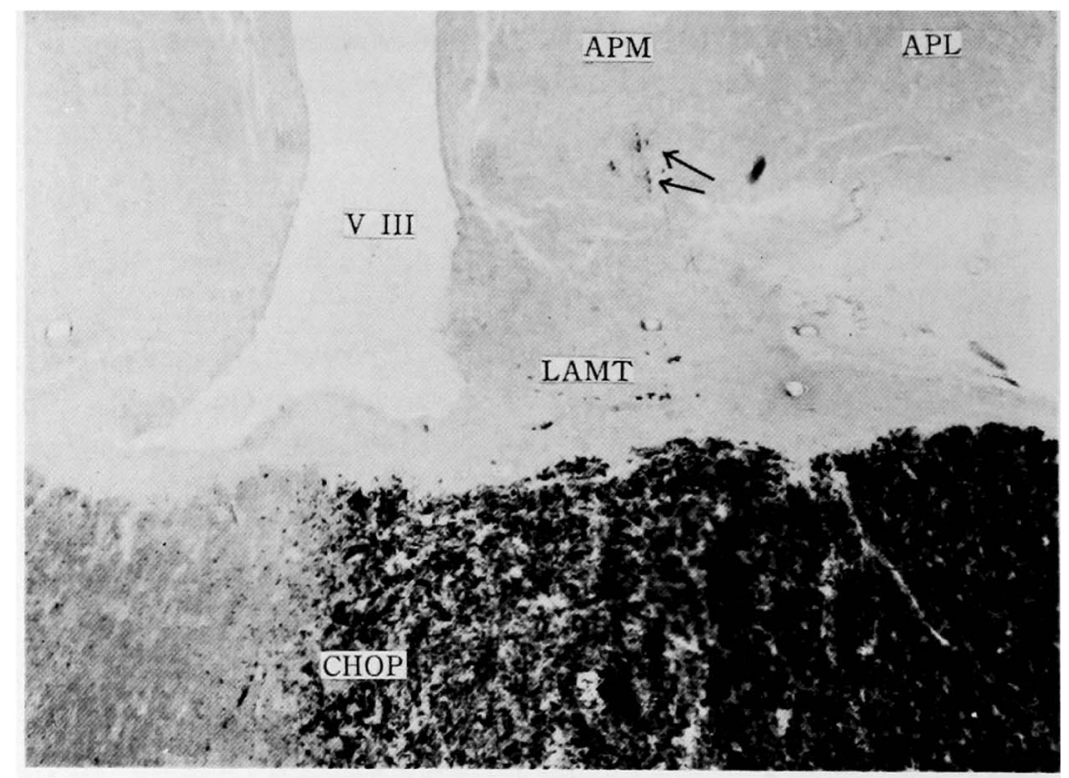

Fig. 2. Terminations of the preoptic component in the lamina terminalis (LAMT) and in the medial preoptic area (APM) are seen on the ipsilateral side. Arrows indicate the termination in the medial preoptic area. Frontal section. Marchi. $\times 100$. 


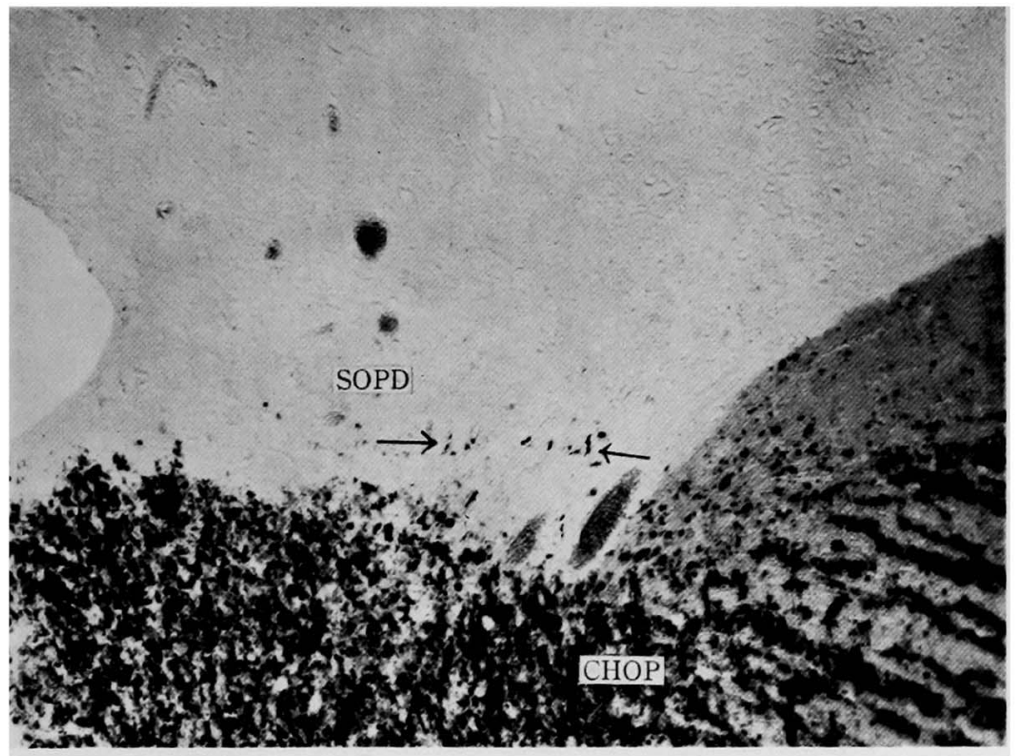

Fig. 3. On the level of the anterior part of the chiasm, supraoptic component is seen to enter the pars dorsolateralis of the contralateral supraoptic nucleus (SOPD). Arrows indicate the termination. Frontal section. Marchi. $\times 100$.

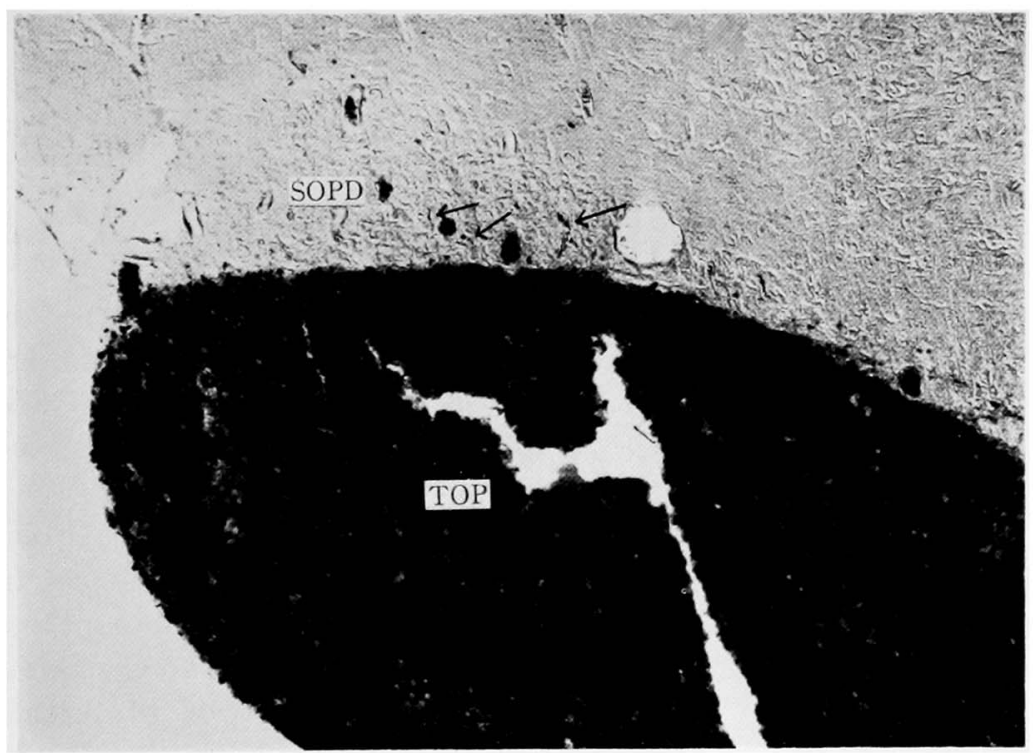

Fig. 4. At the level of the middle of the chiasm, supraoptic component is seen to enter the pars dorsolateralis of the contralateral supraoptic nucleus (SOPD). Arrows indicate the termination. Frontal section. Marchi. $\times 70$. 


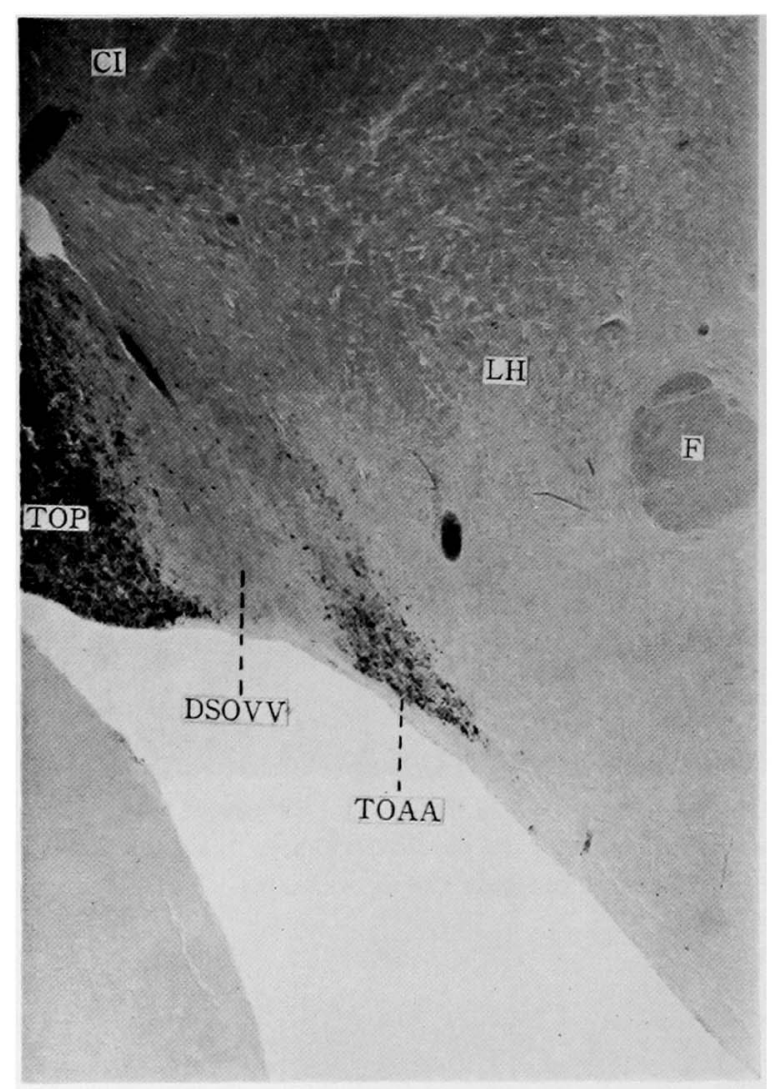

Fig. 5. At the ventral surface of the diencephalon, the anterior accessory optic tract (TOAA) is seen separated from the main optic tract (TOP) by the Gudden's commissure (DSOVV). Frontal section. Marchi. $\times 40$.

Optic fibers of this group are all uncrossed fibers and show no sign of crossing in any part of their course bafore they terminate. Each reinal quadrant takes part in composing this connection, but fibers from the medial or lateral quadrant are more in number than those from the superior or inferior quadrant.

(2) Supraoptic component (Supraop. Comp. in Fig. 12): Directly from the dorsal surface of the chiasm, a few degenerated granules were observed to enter the pars dosolateralis of the supraoptic nucleus which directly overlies the dorsolateral tip of the chiasm. These are sparse and distribute only in the part of the nucleus rather adjacent to the chiasmatic surface (Figs. 3 and 4). Degenerated granules were seen only in the contralateral nucleus. Each retinal quadrant has a share in composing this connection and shows 


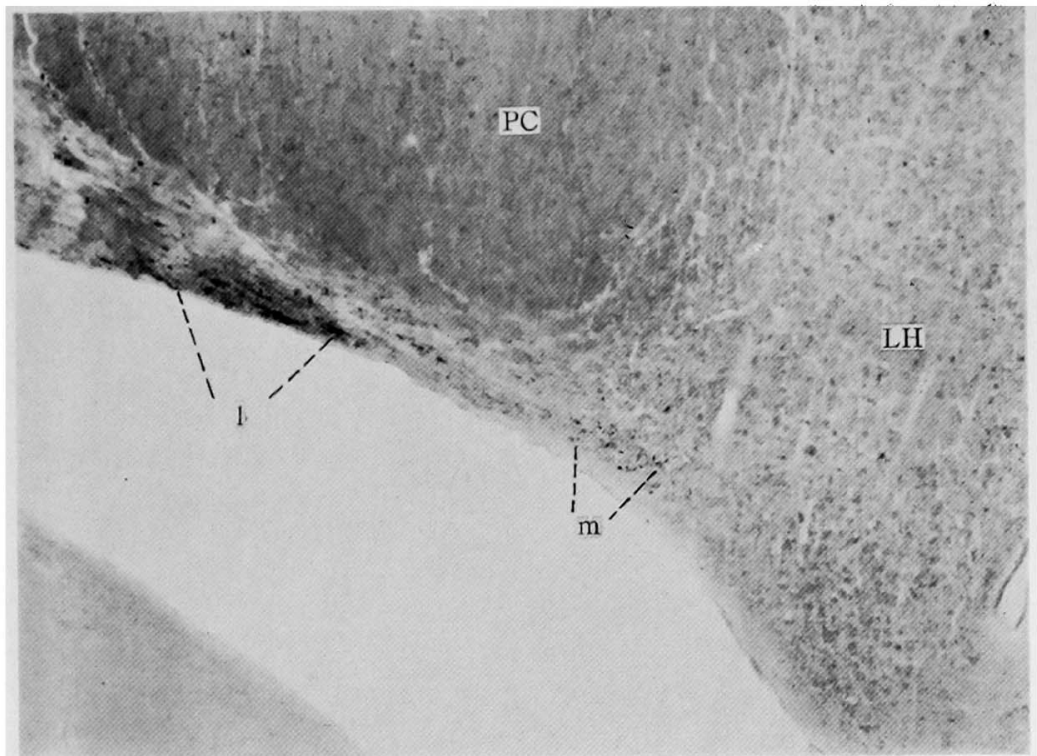

Fig. 6. At the level where the medial margin of the cerebral peduncle (PC) appears on the ventral surface of the diencephalon, the anterior accessory optic tract is divided into a medial (m) and a lateral (1) groups. Frontal section. Marchi. $\times 70$.

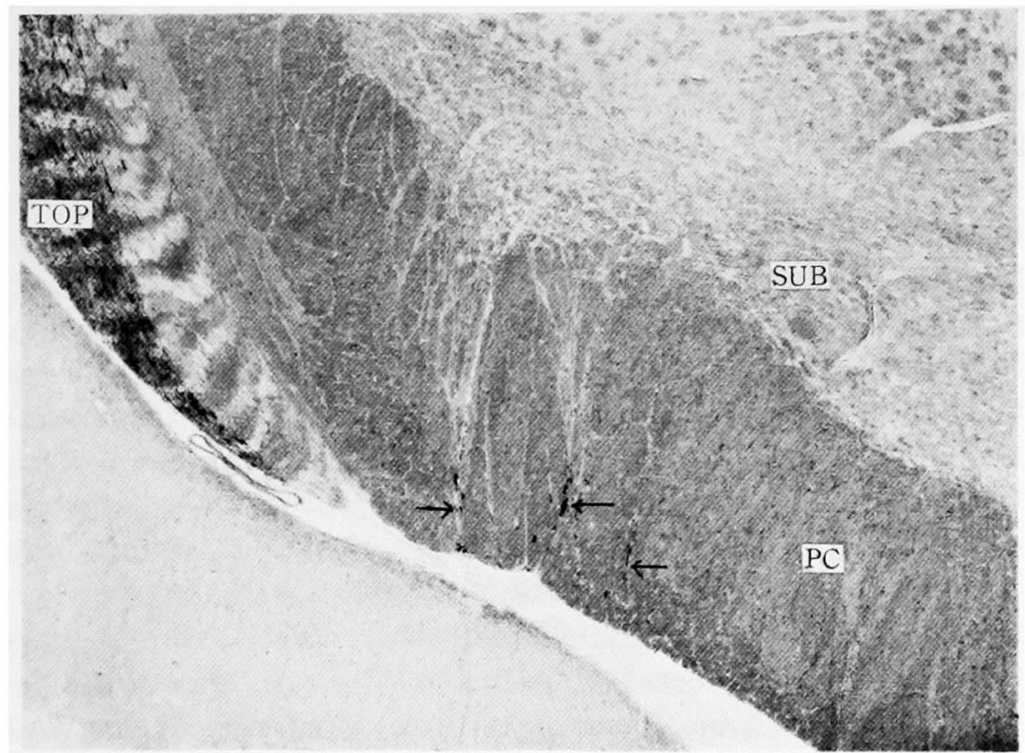

Fig. 7. Lateral group of the anterior accessory optic tract penetrates into the interfibular spaces of the cerebral peduncle (PC). Frontal section. Marchi. $\times 40$. 


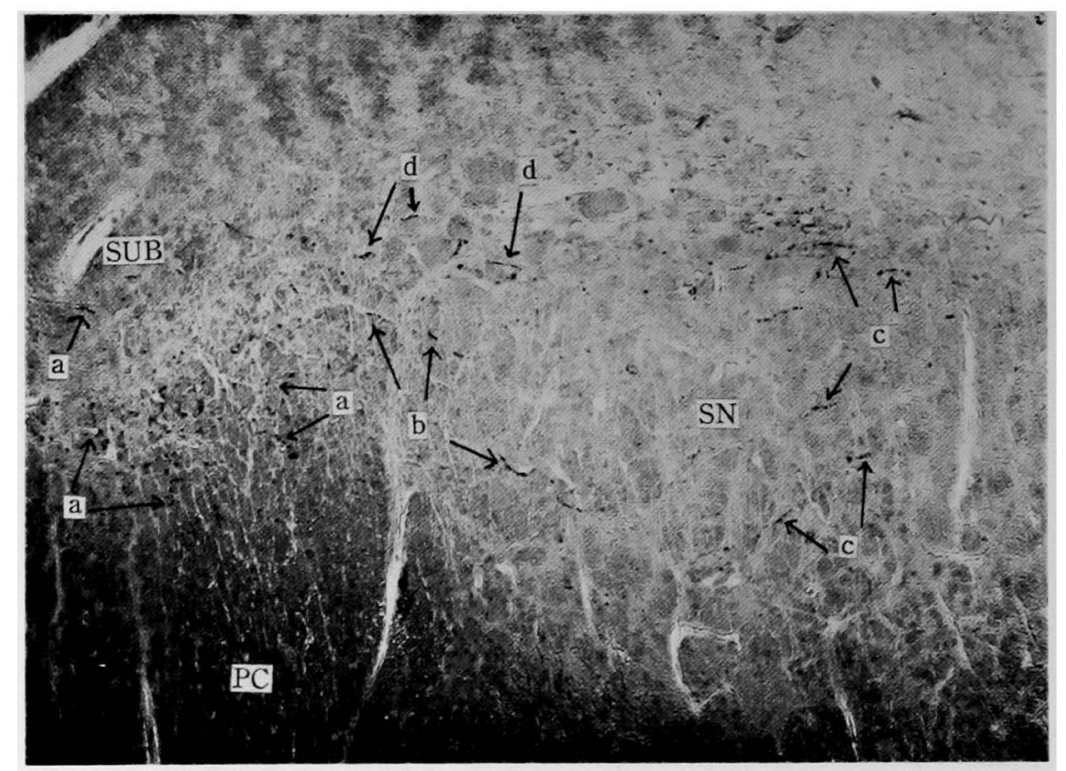

Fig. 8. The anterior and posterior accessory optic tracts are connected in the subthalamic nucleus (SUB) and substantia nigra (SN). a : fibers of the anterior accessory optic tract terminating in the subthalamic nucleus. b: fibers of the anterior accessory optic tract passing into the substantia nigra through the subthalamic nucleus. $c$ : fibers of posterior accessory optic tract terminating in the substantia nigra. $d$ : fibers of the posterior accessory optic tract passing into the subthalamic nucleus through the substantia nigra. Frontal section. Marchi. $\times 80$.

no apparent difference in number or distribution of fibers one another.

(3) Anterior accessory optic tract (TOAA in Fig. 12): On the course of the optic tract from the chiasm caudolateralwards, some degenerated granules which cross in the chiasm most posteoriorly appear gradually to make up a small group, along the ventral surface of the diencephalon, medial to the main optic tract being separated from it by the fibers of the pars ventralis of the ventral supraoptic decussation (Gudden's commissure) (Fig. 5). This group of fibers was identified to be the anterior accessory optic tract. The TOAA proceeds caudad and by the level where the cerebral peduncle appears on the ventral surface of the diencephalon, the TOAA has been divided into a lateral major group and a medial minor group by the medial tip of the cerebral peduncle (Fig. 6). The lateral group passes caudolaterad along the ventrolateral surface of the cerebral peduncle so far as to the middle of its mediolateral extent, where the most of the fibers penetrate through the interfibular spaces of 


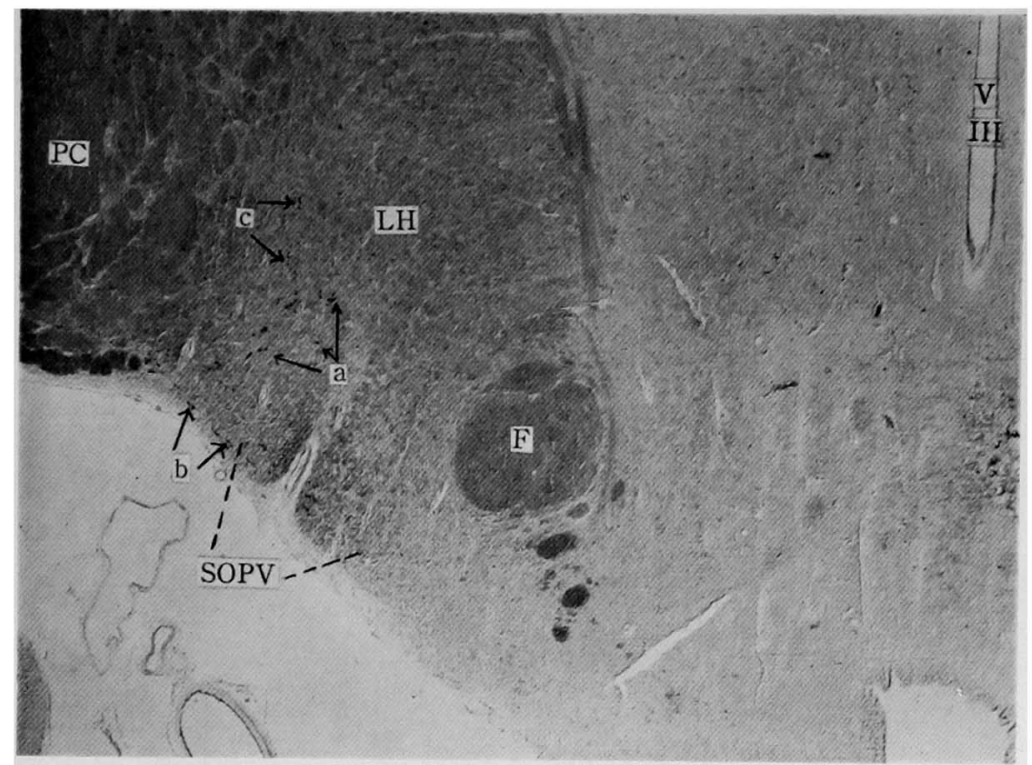

Fig. 9. The medial group of the anterior accessory optic tract. a: fibers terminating in the lateral hypothalamic nucleus $(\mathrm{LH})$. b: fibers terminating in the pars ventromedialis of the supraoptic nucleus (SOPV). c: fibers passing toward the subthalamic nucleus along the medial margin of the cerebral peduncle (PC). Frontal section. Marchi. $\times 50$.

the cerebral peduncle (Fig. 7) to enter the subthalamic nucleus (corpus Luysi) (Fig. 8). Furthermore, a few remaining fibers swinging around the lateral margin of the cerebral peduncle and terminate in the subthalamic nucleus. Observation of the serial sections could make it clear that from the subthalamic nucleus, by far fewer degenerated granules pass more caudad toward the substantia nigra (pars reticularis) than those entering the subthalamic nucleus through the cerebral peduncle (Fig. 8). This finding strongly suggests that the fibers of the TOAA terminated in the subthalamic nucleus and some of them may possibly pass into the substantia nigra to terminate. The fibers of the medial group diverge dorsomediad to terminate in the lateral hypothalamic nucleus, with some of them passing ventromediad along the ventral surface of the diencephalon to terminate in the pars ventromedialis of the supraoptic nucleus, and with a few of them swinging around the medial margin of the cerebral peduncle to enter the subthalamic nucleus (Fig. 9). No degenerated fiber was observed in the position of the TOAA on the ipsilateral side. The TOAA receives fibers from each retinal quad- 


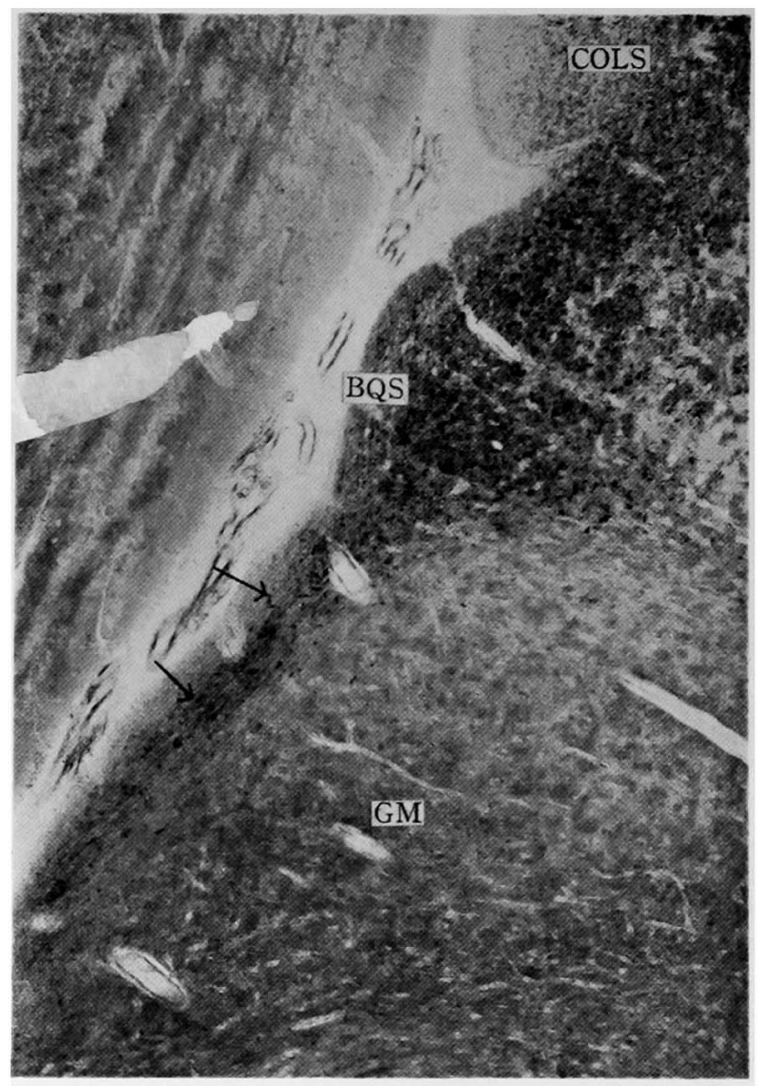

Fig. 10. The posterior accessory optic tract (arrows) is shown to leave the superior quadrigeminal brachium (BQS) onto the lateral surface of the posterior part of the medial geniculate body (GM). Frontal section. Marchi. $\times 40$.

rant and no apparent difference in number or distribution is recognized among different retinal quadrants, so far as observed in our frontal sections.

(4) Posterior accessory optic tract (TOAP in Fig. 12): From the rostrolateral aspect of the superior quadrigeminal brachium, a group of degenerated granules was observed to diverge on to the lateral surface of the posterior part of the medial geniculate body (Fig. 10). This group of fibers was identified to be the posterior accessory optic tract. The TOAP travels ventrolaterad over the lateral surface of the posterior part of the medial geniculate body, then ventromediad along the ventral surface of the cerebral peduncle to arrive at the medial margin of it on the level just rostral to the outlet of the oculomotor nerve, whence the TOAP swings around the medial 


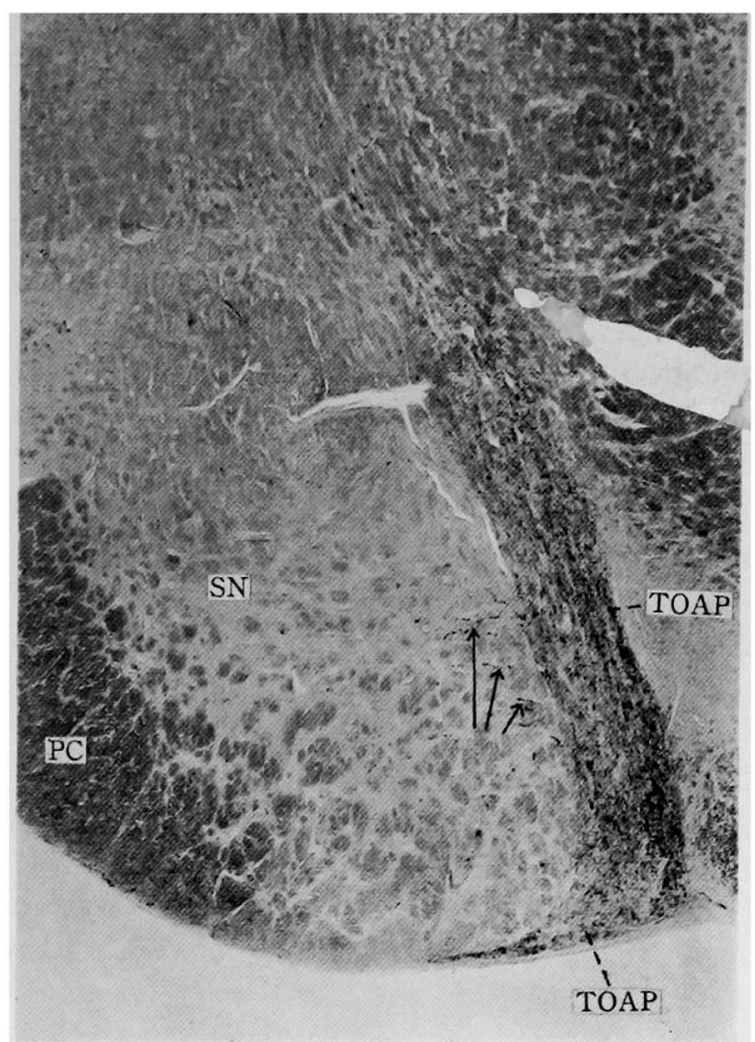

Fig. 11. Terminal part of the posterior accessory optic tract (TOAP). Cells of the terminal nucleus are distributed along the terminal part of the tract. Fibers passing into the substantia nigra $(\mathrm{SN})$ are shown with arrows. Frontal section. Marchi. $\times 40$.

margin of the cerebral peduncle to proceed dorsolaterad to terminate in the nucleus opticus tegmenti ( $\mathrm{T} \mathrm{s}$ a i '25). On the way to this terminal nucleus, the TOAP gives off fibers to the substantia nigra (pars reticularis) on its mediodorsal aspect (Fig. 11). Some of the degenerated granules directed to the substantia nigra seemed to pass toward the subthalamic nucleus through the substantia nigra (Fig. 8). Only on the contralateral side were observed the degenerated granules in the position of the TOAP. Each retinal quadrant sends fibers apparently in equal number and distribution so far as observed in our frontal sections. 


\section{Discussion}

1) Direct retino-hypothalamic connections:

As early as in 1860, Kölliker described already that the optic nerve was connected with the substantia perforata antica, the tuber cinereum and the lamina terminalis, and since then the existence of the direct connections between the retina and the hypothalamus in various mammals has been reported by many authors.

F r e y ('38) observed his 'dorsale hypothalamische Opticuswurzel' in guinea pig which he described to diverge from the dorsal aspect of the chiasm to proceed dorsocaudad, crossing in part, into the medial part of the tuber cinerum. De R e n z i et al. ('59) confirmed the existence of the retino-hypothalamic connection of $\mathrm{Fre} y$ in rat. $\mathrm{Kn}$ och e ('56), however, claimed to have first proved the 'retinohypothalamsches Fasersystem' which he described to be so extensive as to originate in the retina and to terminate in the hypothalamus, and so far as in the posterior lobe of the hypophysis. He proved this connection to be existing experimentally in man, dog and rabbit mainly with Bielschowsky technique. Knoche's view was later confirmed by Blü mcke ('58) in guinea pig and cat with same technique. B l ü m c k stated as to course and termination of this connection that it began at the rostal end of the chiasm to proceed into the lateral wall of the third ventricle through the lamina terminalis and pierced the nuclear region of the tuber cinerum to get to the posterior lobe of the hypophysis. Handa ('51) also observed a few retino-hypothalamic fibers diverging from the rostral end of the chiasm to proceed dorsad along the rostral wall of the optic recess in rabbit and guinea pig with Marchi technique.

What we call with the name of 'preoptic component' is a group of a few retinal fibers diverging from the mediodorsal corner of the optic nerve just rostral to the chiasm, showing no evidence of crossing to the other side, to descend dorsocaudad and laterad almost in parallel with the dorsal surface of the chiasm to finish its course partly in the lamina terminalis and partly more daudally in the preoptic area. Our interpretation of this kind of retino-hypothalamic connection seems most likely to be of the same category as that of $\mathrm{Knoche}$ and $\mathrm{Blüm} \mathrm{me}$ and also as that of $\mathrm{Handa}$ in spite of minute different features. Fr e y's view of the retino-hypothalamic connection does not seem to be of the same category of our present observation, because Frey's dorsal hypothalamic root is situated much more posteriorly and much more in quantity. (his Abb. 35). 


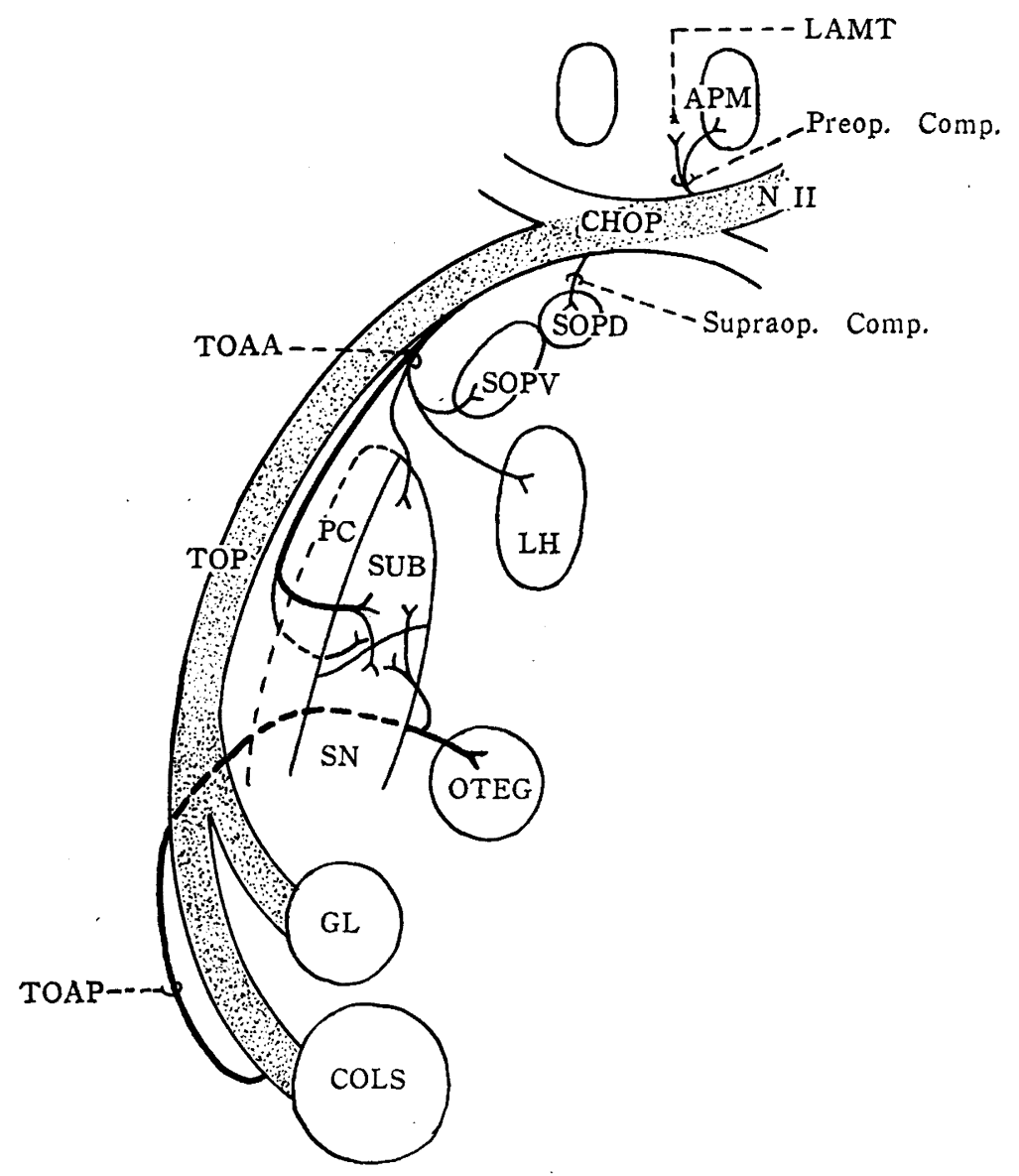

Fig. 12. Diagrammatic summary of the courses and terminations of the accessory optic system. For description see text.

Recent Nauta's technique has failed to demonstrate the retinohypothalamic connection in the sense of $\mathrm{Knoche}$ and $\mathrm{Blumcke}$. $\mathrm{Ha}$ y how ('59) in cat, $\mathrm{Hayhow}$ et al. ('60) in rat and Giolli ('63) in monkey failed to prove the direct retino-hypothalamic connection. If Nauta technique is the method for selective demonstration of degenerated nerve axons whether rich myelinated or poorly myelinated and Marchi technique for the demonstration of degenerated myelin sheath, Nauta technique should reveal all what Marchi technique can. The fact that Nauta technique failed to demonstrate what Marchi technique could, is may-be due to the difference of the postoperative survival period required for each 
technique. Fille $\mathrm{nz}$ et al. ('61) reported that the optic nerve was composed of fibers requiring different time of the postoperative degeneration. Anyhow, this fact is worth bearing in mind for the occasion of interpreting the histological pictures or criticizing the technique itself.

Another category of the direct retino-hypothalamic connection is what we call with the name of 'supraoptic component'. Eding e r ('11) oberved this connection in squirrel and Rouss y et al. ('35) in dog and man. The latter observed a two way connection of this kind and designated as 'fibres rétino-tangentielles' and 'faisceau tangentino-rétinien'. H a n d a ('51) observed retinal fibers entering directly from the chiasm into the pars dorsolateralis of the supraoptic nucleus in rat, rabbit and cat.

$\mathrm{H}$ a $\mathrm{n}$ d a ('51) described the retinal fibers terminating in the nucleus supraopticus diffusus of Gurdjian, but it was not confirmed to be existing in the posent study.

2) Anterior accessory optic tract (TOAA):

This tract was first recognized to be accepted in the mammalian brain by B ochenek ('08) and designated tractus opticus accessorius anterior by the same author. Since then its existence has been confirmed by $\mathrm{Tsa}$ i ('25) in opossum; De $\mathrm{Renzi}$ et al. ('59) in mouse; Las hle y ('34), $\mathrm{H}$ a $\mathrm{nd}$ a ('51) and $\mathrm{Ha} \mathrm{y} \mathrm{how} \mathrm{et} \mathrm{al.} \mathrm{('60)}$ in rat; $\mathrm{Handa}$ ('51) in guinea pig; Loe p p ('12), Ko saka et al. ('15), B rou w e r et al. ('23), H a n d a ('51), G i o lli ('61) and N i i$\mathrm{mi}$ et al. ('61) in rabbit; $\mathrm{Handa}$ ('51) in cat. Negative data in this respect have been given by Bodian ('37) in opossum; Barris et al. ('35), H a y how ('59) in cat ; Brouwer et al. ('26) and Giolli ('63) in monkey.

The TOAA is commonly described as being formed of the late crossing retinal fibers on the ventral basis of the diencephalon and later penetrating the cerebral peduncle to terminate in the subthalamic nucleus (C la r k '42, M e ik le et al. '64). The present study attained the same observation but with some different features as to its course and termination.

$\mathrm{H}$ a n d a ('51) described in rabbit a few fibers diverging into the lateral hypothalamic nucleus from the TOAA, which seem to correspond with the fibers of the medial group in the present observation. Besides the lateral hypothalamic nucleus, fibers of the medial group in the present study were traced along the ventral surface of the hypothalamus into the pars ventromedialis of the supraoptic nucleus and a few of them after swinging around the medial margin 
of the cerebral peduncle into subthalamic nucleus. $\mathrm{Ni}$ i mi et al. ('61) described a few fibers of the TOAA terminating in the 'ventromedial part of the hypothalamus' but we are not sure to say whether or not these correspond with our fibers of the medial group of the TOAA.

L o e p p ('12) described in rabbit that the TOAA penetrated through the cerebral peduncle to terminate in the subthalamic nucleus. This view was confirmed by $\mathrm{Handa}$ ('51) in the same animal, while Kosaka et al. ('15) believed that the TOAA was composed mainly of aberrant optic fibers which later rejoin the main optic tract and of only a few fibers entering the subthalamic nucleus in the same animal. L a s h le y ('34, in rat) and $\mathrm{H}$ a y h o w ('59, in cat) were in accord with the view that the TOAA is mainly composed of aberrant optic fibers. They observed only a few of them passing into the nucleus tractus peduncularis transversi of Bechterew (1899) (nucleus opticus tegmenti of Tsai '25). $\mathrm{H}$ a $\mathrm{y} \mathrm{how}$ did not regard this group of fibers as an accessory optic tract and called this terminal nucleus the medial terminal nucleus.

In the present study fibers of the TOAA were observed to terminate partly in the subthalamic nucleus and partly in the substantia nigra. G i o $11 \mathrm{i}$ ('61, in rabbit), however, believed that the TOAA did not terminate in the subthalamic nucleus but passed through this nucleus to terminate in the nucleus of the transpedunclar tract (nucleus opticus tegmenti, Ts a i 25 ; nucleus tractus pedunclaris transversi, B e c h t e r e w 1899). N i m i et al. ('61, in rabbit) described that the fibers terminated partly in the subthalamic nucleus and partly in his medial terminal nucleus which seemed to correspond with the same nucleus of $\mathrm{Ha} \mathrm{y} \mathrm{how} \mathrm{('59).}$

Giolli ('61) denied the existence of the termination in the subthalamic nucleus in rabbit on the basis of his observation with Nauta technique that no terminal degeneration was seen in the nucleus. In our Marchi preparations of the same animal, it was observed that many degenerated granules disappeared in this nucleus, that is to say, that only a part of the degenerated granules entering this nucleus through the cerebral peduncle found their way through this nucleus toward the substantia nigra. This finding we consider strongly supports the existence of termination in the nucleus. This discrepancy between the findings by Nauta and Marchi technique may be explained by an assumption that the nerve fibers might loose their myelin sheaths in this nucleus. But this assumption lacks in proof. 
3)Posterior accessory optic tract (TOAP):

$\mathrm{G} u \mathrm{~d} d \mathrm{e} \mathrm{n}$ (1870) claimed to have first described this tract $2 \mathrm{o}$ tractus peduncularis transversus and later suggested it to be $c_{n}$ retinal origin (1881). In the subsequent studies this tract has been referred to with various different names. B o c h e n e k ('08) called it fasciculus accessorius optici posterior; Tsai ('25) tractus opticus accessorius posterior; Gillilan ('41) the basal optic root and Gi o lli ('61) the transpeduncular tract.

The TOAP is commonly described as leaving the main optic tract from the ventral pole of the lateral geniculate body on the contralateral side, crossing obliquely over the cerebral peduncle and entering the interpeduncular space to terminate in the nucleus opticus tegmenti ( $\mathrm{Cla} \mathbf{r k}$ '42). Its existence has been confirmed by many authors; Tsai ('25) in opossum; Lashley ('34), Tsang ('37), $\mathrm{Handa}$ ('51) and $\mathrm{De} \mathrm{Renzi}$ et al. ('59) in rat; Walle nberg ('03) and $\mathrm{H}$ a $\mathrm{n} d \mathrm{a}$ ('51) in guinea pig; W a lle $\mathrm{n}$ be r g ('03), L o e p p ('12), Kos a k et al. ('15) B rou wer et al. ('23), Handa ('15), Giolli ('61) and $\mathrm{Ni}$ im i et al. ('61) in rabbit; $\mathrm{Ha} \mathrm{nd} \mathrm{a} \mathrm{('51)} \mathrm{and}$ $\mathrm{Hayhow}$ ('59) in cat; Giolli ('63) in monkey. Negative data have been given also by Brou wer et al. ('23) and Barris et al. ('35) in cat and B rou we r et al. ('26) in monkey.

Most of the authors agree with its general description abovementioned as to its course, but as for the terminations some different interpretations have been presented. Gillil a n ('41) studied in a series of mammals and described an extensively wide distribution of the basal optic root in the midbrain tegmentum. He observed that the fibers terminate in the nucleus of the basal optic root, substantia nigra, lateral reticular area of the midbrain tegmentum, nucleus oculomotorius, capsule of the interpeduncular nucleus, mamillary peduncle and the ipsilateral nucleus of the basal optic root by passing through the supramammilary decussation. In the present study such a wide destribution of the TOAP could not be confirmed. Besides the nucleus opticus tegmenti (nucleus of the basal optic root of Gillila $n$ ), substantia nigra was confirmed to be the site of termination. G i olli ('61) also observed the termination in the substantia nigra in rabbit with Nauta technique.

Through the substantia nigra a few fibers were observed to pass anterolaterad into the subthalamic nucleus, thus establishing the connection between the anterior and posterior accessory optic tracts. The connection between the TOAA and TOAP has been reported by $\mathrm{H}$ a nda ('51) in guinea pig; De $\mathrm{R}$ e $\mathrm{nz}$ i et al. ('59) in 
mouse; Lash ley ('34), $\mathrm{H}$ and a ('51) and $\mathrm{H}$ a y how et al. ('60) in rat; G i olli ('61) and $\mathrm{N}$ i i m i et al. ('61) in rabbit; $\mathrm{H}$ a y how ('59) in cat. $\mathrm{H}$ a y how et al. ('60) claimed to have first revealed the whole accessory optic system stating that hitherto described anterior or posterior accessory optic tract was only a part of the one integral accessory optic system. Both his superior fasciculi (The most posterior of which corresponds with TOAP.) and inferior fasciculus (This corresponds with TOAA.) terminate together in his medial terminal nucleus (nucleus opticus tegmenti of $\mathrm{Ts}$ a i '25). Previous reports are all in accord in the respect that the TOAA and TOAP are connected in the nucleus opticus tegmenti. In the present study, however, the sites of the connection are the subthalamic nucleus and the substantia nigra.

Recent Nauta studies have revealed the existence of synaptic relations between the fibers of TOAP and the nerve cells scattering or making a small group among the tract. Groups of such cells are designated as lateral or dorsal terminal nucleus ( $\mathrm{H}$ a y h o w '59, in cat; $\mathrm{Hayhow}$ et al. '60, in rat; $\mathrm{Ni}$ i mi et al. '61, in rabbit) and the accessory optic nucleus in monkey (G i olli '63). Loepp ('12) described the nucleus parageniculatus to receive retinal fibers. This nucleus may correspond with dorsal terminal nucleus of $\mathrm{Ha}$ how et al. ('60), because of their similar position, namely dorsal to the medial geniculate body along the dorsolateral surface of the mesencephalon. In rabbit, $\mathrm{N}$ i i m i et al. ('61) observed the dorsal and lateral terminal nucleus with Nauta technique, but G i olli ('61) failed to see none of these nuclei in the same animal and with the same technique. Present Marchi findings are in favor of Giolli's and also failed to demonstrate them. Loepp believed that the retinal fibers entered the nucleus parageniculatus because degenerated granules were observed to pass through this nucleus, while in Nauta studies the terminal degenerations certified the description. Even if such nuclei actually do exist, and if only a very small part of the tract terminates in the nucleus which is embedded within the tract, Marchi technique would not be able to reveal the termination surely. This is an important point to be considered in interpreting the Marchi preparations.

4) Regional share of the retina in the composition of the accessory optic system :

Regional share of the retina in the accessory optic system has not been much described. B ro u w e r et al. ('23) examined in rabbit but his description is not precise. Lashley ('34) studied in rat 
and stated that the TOAA received fibers from all quadrants, but especially numerous from the superior-temporal quadrant and TOAP only from the temporal quadrants, both on the contralateral side. Ir our observation the accessory optic system is composed of fibers from all quadrants equally in number and distribution so far as obserbed in the series of the frontal sections except in the case of the preoptic component in which the fibers from the medial or lateral quadrant are more in number than those from the superior or inferior quadrant.

\section{Summary}

1. The accessory optic system in the rabbit was studied by means of Marchi technique.

2. Four groups of retinal fibers were recognized to terminate in the hypothalamus or in the ventral tegmental area of the midbrain, i. e. 1) preoptic component, 2) supraoptic component, 3) anterior accessory optic tract, 4) posterior accessory optic tract.

3. The preoptic component is composed of a small number of uncrossed retinal fibers, leaving the optic nerve at its mediodorsal corner just rostral to the chiasm to descend dorsolaterad almost in parallel with the dorsal surface of the chiasm to finish its course partly in the lamina terminalis and partly further caudally in medial preoptic area. Fibers show no sign of crossing.

4. The supraoptic component is composed of a small number of crossed retinal fibers diverging from the dorsal surface of the chiasm to terminate directly in the pars dorsolateralis of the supraoptic nucleus.

5. The anterior accessory optic tract is composed of the retinal fibers which cross in the chiasm most posteriorly. It appears first medial to the main optic tract on the ventral surface of the diencephalon and then more caudally is divided into a lateral and a medial groups by the medial end of the cerebral peduncle. The lateral group penetrates dorsad through the interfibular spaces of the cerebral peduncle to terminate in the subthalamic nucleus and some of them diverge more caudally into the substantia nigra. The medial group finds its termination in the lateral hypothalamic nucleus and in the pars ventromedialis of the supraoptic nucleus. Sparse fibers are seen to enter the subthalamic nucleus by swinging around the lateral margin of the cerebral peduncle from the lateral group and by swinging around the medial margin from the medial 
group.

6. The posterior accessory optic tract is composed of the crossed retinal fibers first diverging from the superior quadrigeminal brachium to travel along the lateral surface of the diencephalon and then obliquely along the ventral surface of the cerebral peduncle to arrive at the medial end of this where it turns dorsolaterad along the medial margin of the cerebral peduncle to enter the nucleus opticus tegmenti of Ts a i ('25). From the terminal part of this tract in the midbrain tegmentum some fibers are given anterolaterad into the substantia nigra (pars reticularis), a few of which pass into the subthalamic nucleus.

7. It is shown that both the anterior and posterior accessory optic tracts find termination in the subthalamic nucleus and in the substantia nigra, thus establishing the connection between them.

8. The retino-hypothalamic connection is not unitary. The hypothalamus (anatomically and functionally referred to as the SPH-system, B a n '62, '64) receives optic fibers by way of the preoptic component (uncrossed fibers), supraoptic component (crossed fibers) and anterior accessory optic tract (crossed fibers). This is summerized as follows; the retinal fibers terminate in the medial preoptic area and nucleus supraopticus (of the area sympathica-B,) and in the lateral hypothalamic nucleus (of the area parasympathica-C of the SPH-system of B a n, '62, '64).

9. Each retinal quadrant has a share in the composition of the accessory optic system almost in equal quantity and distribution of fibers except in the case of the preoptic component, so far as observed in the series of our frontal sections. For the preoptic component, fibers from the medial or lateral quadrant were observed a little more in number than those from the superior or inferior quadrant.

10. Marchi findings in rabbit were compared with Nauta findings of previous authors in the same animal with consideration of merits and demerits of Marchi technique itself.

\section{References}

1) B a n, T.: Morphological aspects of the hypothalamus, especially on its fiberconnections. Recent Advance in Research of the Nervous System, 6(4): 837-872, 1962 (in Japanese).

2) : The hypothalamus, especially on its fiber connections, and the septopreoptico-hypothalamic system. Med. J. Osaka Univ., 15 : 1-83, 1964.

3) Barris R.W. et al.: Optic connections of the diencephalon and midbrain of 
the cat. J. Comp. Neur., $62: 117-153,1935$.

4) Bechterew, W. von: Die Leitungsbahnen im Gehirn und Rückenmark. Arthur Georgi, Leipzig, 1899 (2te Aufl.). (from p. 218)

5) Blü m cke, S.: Zur Frage einer Nervenfaserverbindung zwischen Retina ur: Hypothalamus. I. Anatomische und experimentelle Untersuchungen an Meerschweinchen und Katzen. Z. Zellforsch., $48: 261-282,1958$.

6) Bochenek, A.: Ueber die zentrale Endigung des Nervus opticus. Anz.d. Akad. Wiss. z. Krakau. 1908. (cited from Ts a i, '25)

7) Bodian, D: An experimental study of the optic tracts and retinal projection of the Virginia opossum. J. Comp. Neur., $66: 113-144,1937$.

8) Brouwer, B. et al.: Experimentell-anatomische Untersuchungen über die Projektion der Retina auf die primären Opticuszentren. Schweiz. Arch. Neur. Psychiat., 13 : 118-138, 1923.

9) - et al.: The projection of the retina in the primary optic neuron in monkeys. Brain, $49: 1-35,1926$.

10) Clark, W.E. Le Gros: The visual centers of the brain and their connections. Physiol. Rev., 22 : 205-232, 1942.

11) De Renzi, C. et al.: Optic projections to the brain stem tegmentum in the mouse. Arch. ital. Biol., 97 : 156-166, 1959.

12) Edinger, L.: Vorlesungen über den Bau der nervösen Centralorgane des Menschen und der Tiere. F.C. W. Vogel, Leipzig, 1911 (8te Aufl.).

13) Fille n $z$, M. et al.: Degeneration of optic nerve fibers in the cat. J. Physiol., $158(2): 18,1961$. (abstract)

14) Frey, E.: Vergleichend-anatomische Untersuchungen über die basale optische Wurzel, die Commissura transversa $\mathrm{Gudden}$ und über eine Verbindung der Netzhaut mit den Vegetativen Gebiet im Hypothalamus durch eine 'dorsale hypothalamische Wurzel' des Nervus opticus bei Amnioten. Schweiz. Arch. Neur. Psychat., $40: 69-126,1938$.

15) Gillila n, L.A.: The connections of the basal optic root (posterior accessory optic tract) and its nucleus in various mammals. J. Comp. Neur., $74: 367-408$, 1941.

16) Giolli, R.A.: An experimental study of the accessory optic tracts (Transpeduncular tracts and anterior accessory optic tracts) in the rabbit. J. Comp. Neur. 117: 77-95, 1961.

17) - : An experimental study of the accessory optic system in the cynomolgus monkey. J. Comp. Neur., $121:$ 89-107, 1963.

18) Gudde n, B. von: Ueber einen bisher nicht beschriebenen Nervenfaserstrang im Gehirne der Säugetiere und des Menschen. Arch. Psych., 2: 364-366, 1870.

19) - Ueber den Tractus peduncularis transversus. Arch. Psych., 11: 415$423,1881$.

20) Handa, Y.: On the relationship between optic tract and hypothalamus. Nōshinkeiryoiki, 9 : 71-85, 1951. (in Japanese)

21) H a y how, W.R.: An experimental study of the accessory optic fiber system in the cat. J. Comp. Neur., 113: 281-313, 1959.

22) et al.: The accessory optic fiber system in the rat. J. Comp. Neur., $115: 187-215,1960$.

23) Kn o che, H.: Morphologisch-experimentelle Untersuchungen über eine Faserverbindung der Retina mit den vegetativen $Z$ entren des $Z_{\text {wischenhirnes }}$ und mit der Hypophyse. Z. Zellforsch., 45 : 201-264, 1956.

24) Kölliker, A.: A manual of human microscopic anatomy. J o hn W. Parker, 
London, 1860. (from p. 236)

25) Kosaka, K. et al.: Zur Anatomie der Sehnervenbahnen und ihres Zentren. Folia Neuro-Biol., 9 : 367-389, 1915.

26) L a shley, K. S.: The mechanism of vision. VII. The projection of the retina upon the primary optic centers in the rat. J. Comp. Neur., $59: 341-373,1934$.

27) L o e p p, W. H. : Ueber die zentralen Opticusendigungen beim Kaninchen. Anat. Anz., $40:$ 309-323, 1912.

28) Me i k le, T.H. et al. : The neural organization of the visual pathway in the cat. Internat. Rev. Neurobiol., 6 : 149-189, 1964.

29) $\mathrm{Ni}$ i m i, K. et al.: The termination of optic fibers in the rabbit as studied by the Nauta method. Acta Anat. Japon., $36: 333,1961$. (abstract, in Japanese)

30) Roussy, G. et al.: L'hypothalamus chez 1'homme et chez le chien. Revue Neur., 63 : 1-35, 1935.

31) Tsa i, C.: The optic tracts and centers of the opossum, Didelphis virginiana. J. Comp. Neur., 39: 173-216, 1925.

32) Tsang, Y.C.: Visual centers in blinded rats. J. Comp. Neur., 66: 211-251, 1937.

33) W a 11 en berg, A.: Notiz zur Anatomie des Tractus peduncularis transversus beim Meerschweinchen. Anat. Anz., 24 : 199-200, 1903. 